\section{Look for the little bit extra}

\section{Catherine Geissler \& T.A.B. Sanders}

Food Reviews International: Production, Processing, Acceptance, Nutrition and Health. Editors Roy Teranishi and Irwin Hornstein. Dekker. 3/yr. \$125 (institutional), $\$ 62.50$ (individual).

Food Additives and Contaminants: Analysis, Surveillance, Evaluation, Control. Editors R. Walker and M.E. Knowles. Taylor \& Francis. 4/yr. £55, \$99.

THE aim of Food Reviews International is to bring together "state of the art reviews in food production, food processing and food related disciplines". The journal is "dedicated to those who strive to create a better nourished and healthier world", and to a certain extent the composition of the editorial board justifies the International in its title. Most of the board is drawn from Europe and the United States, but while Asia, especially Japan, is also well represented, there is no African member and only one from Latin America.

Only reviews are published. Each issue contains three or four of them, ranging in length from 20 to 70 pages. Speed of publication is not indicated. The standard of production, however, is excellent: good quality paper, with clear print, diagrams and half-tones.

The contributions published in the three issues available for review have had an emphasis on the Third World, several of them dealing with rice. Those in the area of food science and technology have given a lot of detail on chemical composition, and much technical information, while those on food production and nutrition have covered broader economic and social matters. To date the former have predominated, but this might well not be the case in the future.

All of the articles could have been published elsewhere, and what distinguishes the journal is not their specific content but its concentration on the lengthy review

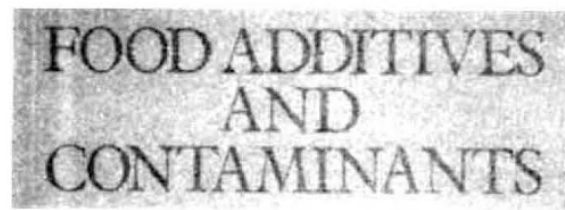

format and the juxtaposition of discussion of all aspects of food, from production through processing to consumption and nutrition. How will it fare?The readership may be limited as it is likely to appeal mainly to food scientists and nutritionists with a particular interest in Third World issues. That is a rather diffuse and limited audience, and the expense of an additio- nal journal could deter libraries in the poorer countries.

By contrast Food Additives and Contaminants has a very well defined constituency. It is concerned primarily with food safety and covers all aspects of additives and contaminants, both artificial and natural, in the food chain. Because of its multidisciplinary nature this journal does indeed fill a gap in the literature.

Short and long papers and reviews are accepted, with a high proportion of them coming from government-funded bodies. Publication time is about six months. Although many of the contributions deal with methodology, and could have appeared in publications such as the

\section{Biological bytes}

\section{Andrew Coulson}

CABIOS: Computer Applications in the Biosciences. Executive editors R.J. Beynon and Joseph L. Modelevsky. IRL. 4/yr. UK £55, North America $\$ 95$ (institutional); UK $£ 30$, North America $\$ 50$ (individual).

$C A B I O S$ is an A4-format quarterly with about 200 pages per issue. Its intended coverage is adequately described by its subtitle; in practice it is concerned mainly with molecular biology and biochemistry rather than statistics, structure-related computing, clinical applications or population biology.

About half of each issue is taken up with reviews of books and software, news and other ephemeral material. A novel feature is the "literature survey", which consists of abstracts of related papers in other periodicals. At first sight this is useful and impressive, since it is said to be compiled by one person and it refers to a variety of sources, some very obscure. However, there appears to be no mention of the intended journal coverage of this section ("what can I avoid scanning by reading this instead?"). My confidence that the compilation is highly systematic was undermined by finding two different abstracts of the same paper in successive issues of the journal.

The original content of each issue consists of about half-a-dozen full papers, perhaps one half-length "Communication", a (commissioned) review and an elementary review ("First Byte").

Publications in this field are often devalued by three features. The size of the MPU (minimum publishable unit) is about 20 per cent of its value in conventional biological science; there is only a weak taboo on publication of similar material in different journals (or in the same journal at intervals of a few months); and many publications describe implementations of
Analyst, the journal also publishes work containing surveillance-type information. The latter, although of great importance, would not be regarded as novel or contributing to the development of new scientific hypotheses by some established journals.

Food Additives and Contaminants is well produced, there are no page charges and the subscription rate is reasonable. Altogether, libraries concerned with food safety and analytical chemistry would do well to have it on their shelves.

Catherine Geissler and T.A.B. Sanders are in the Department of Food and Nutritional Sciences, King's College London (KQC), Campden Hill Road, London W8 $7 A H$, UK.

well-known procedures on particular systems, and contain little that is novel in methods or results. I would award CABIOS $\alpha \beta$ in avoiding these pitfalls. A very high proportion of the papers in the first year dealt with interesting and useful projects which were otherwise unknown to me, and the reviews have been generally timely and well-done.

However, despite the statement in the Instructions to Authors that "preference will be given to papers that describe new algorithms", the principal novelty in most of these papers is not in the algorithm, but

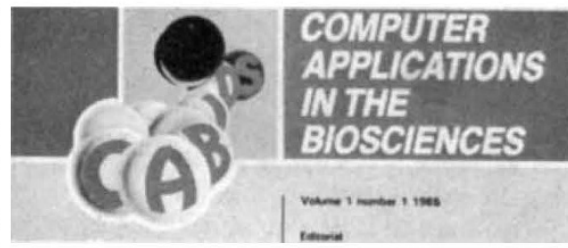

in its specific implementation. Publications of this kind are almost without value if the programs described are not readily available to the reader. The novel procedure $C A B I O S$ has adopted is to make it a condition of publication that authors participate in a Reader Enquiry Service (such as many magazines provide for their advertisers) and make software available at no more than a nominal handling charge. Some software in this area has been sold at such outrageous prices that this rule almost deserves to be described as a courageous decision. No doubt it accounts for the absence of some wellknown names from the journal.

The format is generally attractive and readable. The lack of copy editing is not without visible effect but it enlivens one's reading to come across a word like "esqueleton" in a paper, and I can certainly tolerate incidents like this or finding several pages bound upside down and backwards if the effect is to keep the price of the journal down.

Andrew Coulson is a Lecturer in the Department of Molecular Biology, University of Edinburgh, King's Buildings, Mayfield Road, Edinburgh EH9 $3 J R, U K$. 